\title{
Papers
}

\section{Metformin in polycystic ovary syndrome: systematic review and meta-analysis}

Jonathan M Lord, Ingrid H K Flight, Robert J Norman

\begin{abstract}
Objective To assess the effectiveness of metformin in improving clinical and biochemical features of polycystic ovary syndrome.

Design Systematic review and meta-analysis. Data sources Randomised controlled trials that investigated the effect of metformin compared with either placebo or no treatment, or compared with an ovulation induction agent.

Selection of studies 13 trials were included for analysis, including 543 women with polycystic ovary syndrome that was defined by using biochemical or ultrasound evidence.
\end{abstract}

Main outcome measure Pregnancy and ovulation rates. Secondary outcomes of clinical and biochemical features of polycystic ovary syndrome.

Results Meta-analysis showed that metformin is effective in achieving ovulation in women with polycystic ovary syndrome, with odds ratios of 3.88 (95\% confidence interval 2.25 to 6.69) for metformin compared with placebo and 4.41 (2.37 to 8.22) for metformin and clomifene compared with clomifene alone. An analysis of pregnancy rates shows a significant treatment effect for metformin and clomifene (odds ratio 4.40, 1.96 to 9.85). Metformin has an effect in reducing fasting insulin concentrations, blood pressure, and low density lipoprotein cholesterol. We found no evidence of any effect on body mass index or waist:hip ratio.

Metformin was associated with a higher incidence of nausea, vomiting, and other gastrointestinal disturbance.

Conclusions Metformin is an effective treatment for anovulation in women with polycystic ovary syndrome. Its choice as a first line agent seems justified, and there is some evidence of benefit on variables of the metabolic syndrome. No data are available regarding the safety of metformin in long term use in young women and only limited data on its safety in early pregnancy. It should be used as an adjuvant to general lifestyle improvements and not as a replacement for increased exercise and improved diet.

\section{Introduction}

Polycystic ovary syndrome is characterised by anovulation, infertility, and hyperandrogenism, with clinical manifestations of irregular menstrual cycles, hirsutism, and acne. The condition affects an estimated $5-10 \%$ of women of reproductive age, ${ }^{12}$ although this varies depending on the diagnostic criteria used. ${ }^{3}$ One of the commonest presenting complaints of women with polycystic ovary syndrome is anovulatory infertility. They also have increased prevalence of cardiovascular risk factors similar to that seen in the metabolic syndrome (which, like polycystic ovary syndrome, is characterised by insulin resistance ${ }^{4}$ ). By the age of 40 , up to $40 \%$ will have type 2 diabetes or impaired glucose tolerance. ${ }^{5}$ Polycystic ovary syndrome is therefore an important health concern and may represent a major health issue affecting young women today.

The use of metformin for women with polycystic ovary syndrome has aroused a tremendous amount of interest. Several detailed literature reviews report large numbers of trials, although most of these are uncontrolled, have small numbers of participants, and have no allocation concealment. ${ }^{6-11}$ This review aims to answer the question whether metformin is effective in treating women with polycystic ovary syndrome, by amalgamating the trials whose methods are of the highest quality so that meta-analysis can produce valid results.

\section{Methods}

We included randomised controlled trials of metformin compared with placebo, no treatment, or ovulation inducing agents in women with polycystic ovary syndrome. We included trials only if polycystic ovary syndrome was defined by using biochemical or ultrasound evidence. We also included studies of metformin in conjunction with an ovulation inducing agent compared with placebo, no treatment, or an ovulation inducing agent.

We searched the trials register of the Cochrane menstrual disorders and subfertility group in December 2002, the Cochrane central register of controlled trials (Cochrane Library, Issue 4, 2002), Medline (January 1966 to December 2002), and Embase (January 1985 to December 2002). We also handsearched the reference sections of all the randomised controlled trials obtained.

One reviewer screened the titles and abstracts of the randomised controlled trials that we identified. Full text articles were obtained for those trials that fulfilled the inclusion criteria or for which insufficient
Department of Endocrinology and Metabolism, Peninsula Medical School, South West Centre for Reproductive Medicine, Derriford Hospital, Plymouth, Devon, PL6 8DH Jonathan M Lord specialist registrar Consumer Science Program, Commonwealth Scientific and Industrial Research Organisation, Health Sciences and Nutrition, $\mathrm{PO}$ Box 10041, Adelaide, SA 5000, Australia Ingrid H K Flight research officer continued over

bmj.com 2003;327:951

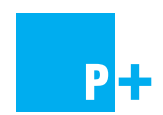

This review is an edited version of that published as a Cochrane review in the Cochrane

Library 2003, Issue 3 (wWw. cochranelibrary.net) Cochrane reviews are regularly updated as new evidence emerges and in response to comments and criticisms, and the Cochrane Library should be consulted for the most recent version of the review. 
Reproductive Medicine Unit, Department of Obstetrics and Gynaecology, University of Adelaide, Queen Elizabeth Hospital, Woodville Road, Woodville, SA 5005 Australia

Robert J Norman professor

Correspondence to: J M Lord jonathan.lord@ pms.ac.uk information was given. The methods section was then sent to another reviewer after all information had been removed that could identify the authors, the publisher, or the results of the study. Both reviewers independently assessed whether the studies met the inclusion criteria; disagreements were resolved by discussion and final arbitration by RJN and the Cochrane editorial base. We sought further information from the authors where papers contained insufficient information to make a decision about eligibility or quality.

We performed statistical analyses according to the statistical guidelines for reviewers in the Cochrane menstrual disorders and subfertility group. We undertook sensitivity analyses to examine the stability of the results in relation to quality of allocation concealment, blinding, obesity, length of treatment over two months, dose of metformin, and ethnic group. Data from crossover trials were used only from the first phase (before crossover).

\section{Description of studies}

Twenty randomised controlled trials met the initial eligibility criteria. We excluded seven studies, leaving 13 to be included in the analysis, of which 10 were double blind, ${ }^{12-21}$ two were single blind, ${ }^{22}{ }^{23}$ and one we presumed to be unblinded. ${ }^{24}$

The diagnosis of polycystic ovary syndrome broadly followed the consensus criteria from the National Institutes of Health of anovulation and hyperandrogenaemia, with exclusion of other endocrinopathies, in all but three trials that used ultrasound criteria. $^{121724}$ All of the included trials required oligomenorrhoea or proved anovulation, and all of these trials excluded other endocrinopathies.

\section{Results}

\section{Clinical outcomes}

Clinical pregnancy rate

Care is needed in interpreting pregnancy rates as no trial had pregnancy as a primary outcome measure, and only six of the trials had tubal disease or male factor infertility, or both, as exclusion criteria. ${ }^{14} 1517202124$ Six of the nine trials reporting pregnancy rates were of less than four months' duration. ${ }^{142217212012}$

\section{Comparison: Metformin versus placebo or no treatment (clinical outcomes)} Outcome: Ovulation rate

\begin{tabular}{|c|c|c|c|c|c|c|}
\hline \multirow{2}{*}{$\begin{array}{l}\text { Study } \\
\text { Fleming } 2002\end{array}$} & \multirow{2}{*}{$\begin{array}{c}\text { Treatment } \\
\text { n/N } \\
37 / 45\end{array}$} & \multirow{2}{*}{$\begin{array}{c}\text { Control } \\
\text { n/N } \\
30 / 47\end{array}$} & \multicolumn{2}{|c|}{$\begin{array}{l}\text { Peto odds ratio } \\
\text { (95\% fixed) }\end{array}$} & \multirow{2}{*}{$\begin{array}{c}\text { Weight } \\
\% \\
35.4\end{array}$} & \multirow{2}{*}{$\begin{array}{c}\text { Peto odds ratio } \\
\text { (95\% Cl fixed) } \\
2.51 \text { (1.01 to } 6.25)\end{array}$} \\
\hline & & & & 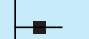 & & \\
\hline Jakubowicz 2001 & $8 / 28$ & $0 / 28$ & & & 13.4 & 9.89 (2.24 to 43.61$)$ \\
\hline Nestler 1996 & $5 / 11$ & $1 / 13$ & & & 9.0 & 6.89 (1.12 to 42.33$)$ \\
\hline Nestler 1998 & $12 / 35$ & $1 / 26$ & & 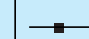 & 19.6 & 5.96 (1.74 to 20.38) \\
\hline Ng 2001 & $3 / 9$ & $3 / 9$ & & & 8.1 & $1.00(0.15$ to 6.72$)$ \\
\hline Vandermolen 2001 & $1 / 12$ & $1 / 15$ & & & 3.7 & $1.26(0.07$ to 21.72$)$ \\
\hline Yarail 2002 & $6 / 16$ & $1 / 16$ & & $\Rightarrow$ & 10.9 & 5.88 (1.13 to 30.61$)$ \\
\hline Total $(95 \% \mathrm{Cl})$ & $72 / 156$ & $37 / 154$ & & - & 100.0 & 3.88 (2.25 to 6.69$)$ \\
\hline \multicolumn{3}{|c|}{ Test for heterogeneity: $\chi^{2}=6.05, \mathrm{df}=6, \mathrm{P}=0.42$} & $0.01 \quad 0.1$ & 10 & 100 & \\
\hline \multicolumn{3}{|c|}{ Test for overall effect: $z=4.89, P<0.00001$} & $\begin{array}{l}\text { Favours } \\
\text { control }\end{array}$ & & $\begin{array}{l}\text { /ours } \\
\text { ment }\end{array}$ & \\
\hline
\end{tabular}

Fig 1 Metformin compared with placebo or no treatment-ovulation rate
The clinical pregnancy rate reported by five trials comparing metformin with placebo did not show evidence of benefit (odds ratio 2.76, 95\% confidence interval 0.85 to $8.98, \mathrm{P}=0.09$ ). ${ }^{12} 14172122$ We found no significant heterogeneity, but the funnel plot was asymmetrical, which raised the possibility of publication bias. In the three trials comparing clomifene with metformin compared with clomifene alone, we found a significant effect for metformin with clomifene (4.40, 1.96 to $9.85, \quad \mathrm{P}=0.0003){ }^{141524}$ We detected no heterogeneity.

Ovulation rate

Overall, as figure 1 shows, a significant effect of metformin compared with placebo on ovulation became obvious $(3.88,2.25$ to $6.69, \mathrm{P}<0.0001)$. We detected no significant heterogeneity. The funnel plot was limited as only seven trials were included, but no bias was evident. The two trials with the lowest weight (total weight $11.8 \%$ ) are the two that did not show a significant effect.

Figure 2 shows that the effect for metformin and clomifene compared with clomifene alone was also significant $(4.41,2.37$ to $8.22, \mathrm{P}<0.0001)$ based on the results of three trials. However, we detected significant heterogeneity. Two of the trials used participants who were known to have been resistant to clomifene previously, and consequently the ovulation rate in their placebo and clomifene arms was relatively low $(17.5 \%) .^{14}{ }^{15}$ These two trials showed a significant effect for metformin and clomifene compared with clomifene and placebo (9.34, 3.97 to $21.97, \mathrm{P}<0.00001)$, without any heterogeneity. In contrast the third trial, where participants were not selected on the basis of being resistant to clomifene, had a high ovulation rate in their placebo and clomifene arm (64\%). ${ }^{24}$ This trial did not show evidence of benefit for metformin compared with clomifene in our analysis when odds ratios were used, although it did in the original report.

\section{Weight}

We found no evidence of effect from metformin on body weight or body mass index. Only one trial reported waist circumference. ${ }^{18}$ We found no evidence of an effect by metformin on waist circumference, nor on waist:hip ratio, as reported by seven trials with minimal heterogeneity. ${ }^{12} 131416221821$

\section{Blood pressure}

Two trials comparing metformin with placebo reported blood pressure. ${ }^{162}$ Analysis showed a significant reduction for metformin in both systolic blood pressure (weighted mean difference $-9.07,95 \%$ confidence interval -14.98 to $-3.15, \mathrm{P}=0.003)$ and diastolic blood pressure $(-5.69,-9.66$ to $-1.73, \mathrm{P}=0.005)$. We detected no heterogeneity between the two trials, but the total number of participants was only 47 .

\section{Adverse events}

Only one trial reported miscarriage rates and multiple pregnancy rates. ${ }^{20}$ Neither reached significance.

Four trials included details about side effects that are suitable for analysis (fig 3). ${ }^{1617}{ }^{16}$ One trial used metformin for six weeks ${ }^{12}$ wheras the others used it for 12 weeks or more. Metformin caused a significantly higher incidence of nausea or vomiting (odds ratio 


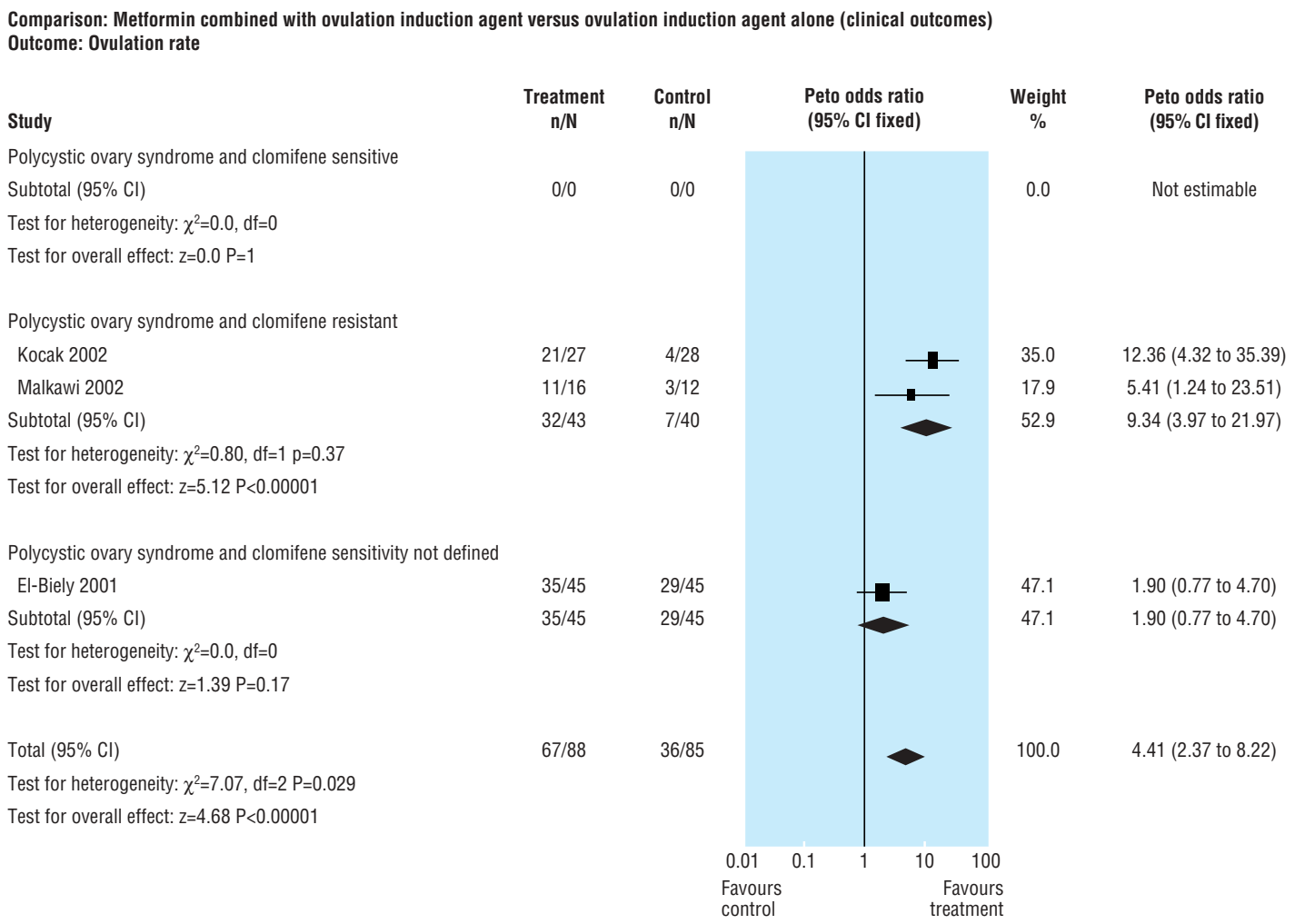

Fig 2 Metformin combined with clomifene compared with clomifene alone-ovulation rate

$3.84,95 \%$ confidence interval 1.07 to $13.81, \mathrm{P}=0.05$, and other gastrointestinal disturbance $(4.40,1.82$ to $10.66, \mathrm{P}=0.003)$. We detected no heterogeneity in the results. One trial reported that most of their dropouts were because of gastrointestinal disturbance. ${ }^{12}$ No trial reported any serious adverse events.

\section{Biochemical outcomes}

Insulin

Metformin had a significant effect in reducing fasting insulin concentrations with a weighted mean difference of -5.37 ( -8.11 to $-2.63, \mathrm{P}=0.0001$ ) (fig 4 ). Overall nine trials were included in the analysis, and all

Comparison: Metformin versus placebo or no treatment (clinical outcomes) Outcome: Adverse events (miscarriage, multiple pregnancy, side effects)

\section{Study}

Nausea and vomiting

Moghetti 2000

$\mathrm{Ng} 2001$

Yarali 2002

Subtotal $(95 \% \mathrm{Cl})$

Test for heterogeneity: $\chi^{2}=0.02, d f=2 P=0.99$

Test for overall effect: $z=1.93 \quad P=0.05$

Gastrointestinal disturbance (other than nausea and vomiting)

Fleming 2002

Moghetti 2000

$\mathrm{Ng} 2001$

Subtotal $(95 \% \mathrm{Cl})$

Test for heterogeneity: $\chi^{2}=0.11, \mathrm{df}=2 \mathrm{P}=0.94$

Test for overall effect: $z=3.02 P=0.003$

$\begin{array}{cc}\begin{array}{c}\text { Treatment } \\ \mathbf{n} / \mathbf{N}\end{array} & \begin{array}{c}\text { Control } \\ \mathbf{n} / \mathbf{N}\end{array} \\ & \\ 5 / 11 & 2 / 12 \\ 3 / 9 & 1 / 9 \\ 1 / 16 & 0 / 16 \\ 9 / 36 & 3 / 37\end{array}$

$3 / 37$

$\begin{array}{cc} & \\ & \\ 15 / 45 & 5 / 47 \\ 2 / 11 & 0 / 12 \\ 2 / 9 & 0 / 9 \\ 19 / 65 & 5 / 68\end{array}$

trol
$1 / 9$
6





574
$0 / 12$
$5 / 68$

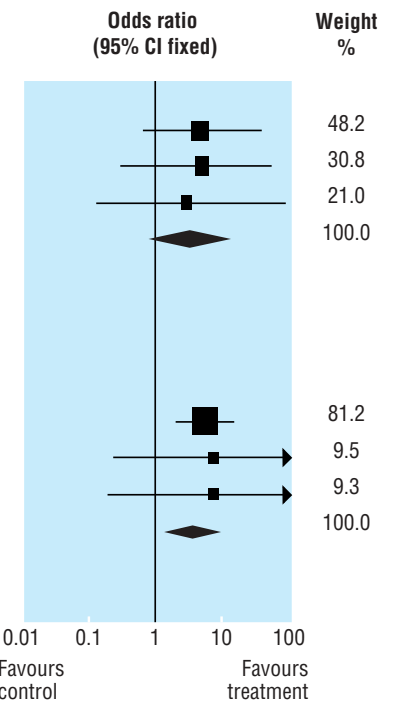

Odds ratio ( $95 \%$ Cl fixed)

$4.17(0.61$ to 28.62$)$ $4.00(0.33$ to 48.66$)$ $3.19(0.12$ to 84.44$)$ 3.91 (0.98 to 15.64$)$

4.20 (1.38 to 12.81$)$ $6.58(0.28$ to 153.75$)$ $6.33(0.26$ to 152.87$)$ 4.62 (1.71 to 12.51$)$

Fig 3 Metformin compared with placebo or no treatment-side effects 
Comparison: Metformin versus placebo or no treatment (biochemical outcomes) Outcome: Fasting insulin (m IU/I)

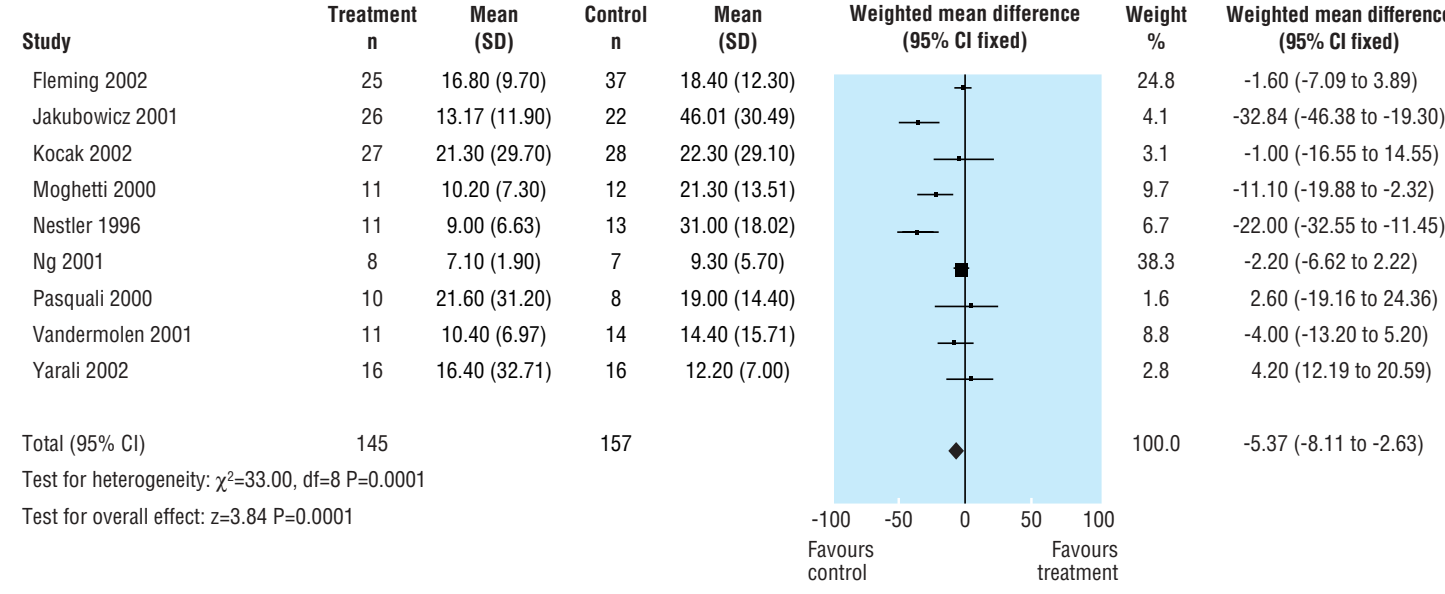

Fig 4 Metformin compared with placebo or no treatment-fasting insulin

had wide confidence intervals. ${ }^{12} 1314161718202122$ Significant heterogeneity was attributable to the large treatment effect seen in two trials. ${ }^{1322}$ When these trials were excluded, the significance remained without significant heterogeneity, which implies a genuine effect of treatment. The funnel plot implies publication bias, although the symmetry is improved when the two trials are excluded from the analysis.

Lipids

Effects on serum concentrations of cholesterol and lipids were reported by three trials with a total of 98 participants. ${ }^{12} 1617$ Total cholesterol showed no evidence of a significant treatment effect with metformin, but low density lipoprotein cholesterol was significantly reduced in the metformin group, with a weighted mean difference of $-0.44(-0.79$ to -0.08 , $\mathrm{P}=0.02)$. We detected no significant heterogeneity, although none of the trials showed a significant treatment effect of their own. We found no evidence of an effect on high density lipoprotein cholesterol from metformin. We also found no evidence of an effect on triglyceride concentrations.

\section{Discussion}

Metformin is effective in achieving ovulation in women with polycystic ovary syndrome. Meta-analysis is valid only if the included participants of all the different studies represent the same overall population. We included only studies of women who have clearly defined polycystic ovary syndrome. The baseline characteristics of the participants from all the trials are similar and represent a population of women with hyperandrogenic anovulation who are mostly overweight and have insulin resistance. We believe that this population is well recognised worldwide and that the results of this meta-analysis are applicable to this whole group of women. We found a reasonable number of trials with good methods, and we found no evidence of significant publication bias.

Limitations

This review has some limitations. Differences between trial populations have resulted in heterogeneity in some of the analyses as discussed above. Several of the results are constrained by small numbers and wide standard deviations, which limits confidence in drawing conclusions. Although sensitivity analyses using various variables did not alter the conclusions fundamentally, some of the planned analyses were constrained owing to the limited number of trials available. Another concern is that the trials were of varying duration, and meta-analysis will imply that treatment effect is similar in all trials whatever their length of treatment and follow up. However, metformin has its effect relatively quickly, ${ }^{13}{ }^{20-23}$ and analysis shows no correlation between length of trial and proportion ovulating with metformin alone among the included trials $(r=0.39, \mathrm{P}=0.39)$. Conversely the correlation between trial length and proportion ovulating with placebo is significant $(r=0.83, \mathrm{P}=0.02)$, and analysis of trials of varying length will therefore tend to produce a conservative estimate of the treatment effect for metformin compared with placebo.

\section{Strengths}

The meta-analysis shows that metformin is effective in achieving ovulation in women with polycystic ovary syndrome. Ovulation was achieved in $46 \%$ of those who received metformin alone (compared with $24 \%$ who received placebo), with a number needed to treat (NNT) of 4.4. Where metformin and clomifene were compared with clomifene alone, ovulation occurred in $76 \%$ of women receiving metformin and clomifene, compared with $42 \%$ of those receiving clomifene alone. The number needed to treat is 3.0, with a range of 1.6 in the trial with the lowest rate of ovulation with clomifene alone (the participants were selected as having been previously resistant to clomifene) to 8.6 in a trial in which the participants' previous sensitivity to clomifene was unknown.

These data seem robust with no evidence of major publication bias. Although the combination of metformin with clomifene results in higher ovulation rates, analysis is robust only in those participants who were known to be resistant to clomifene previously. Other reviews have described ovulation rates of $40-85 \%$ with clomifene alone, although resistance to 
clomifene is more prevalent in women who are overweight, which is a common situation in women with polycystic ovary syndrome. ${ }^{25}{ }^{26}$ A known adverse effect of clomifene alone is an increase in rates of multiple pregnancies, ${ }^{27}$ but as yet no data imply that this also applies to the combination of metformin with clomifene.

Pregnancy rates are harder to interpret in the meta-analysis, and no trial had live birth rate as a defined outcome measure. We found evidence of effect for metformin with clomifene, but few trials had pregnancy as a defined outcome measure, few controlled for other causes of infertility, and the possibility of publication bias limits confidence in this analysis.

\section{Possible recommendations}

Polycystic ovary syndrome is known to be characterised by insulin resistance. Insulin resistance is thought to be a key factor in the development of the metabolic syndrome that is associated with an increased risk of cardiovascular disease. ${ }^{28}$ If metformin were to improve the variables associated with the metabolic syndrome in women with polycystic ovary syndrome, then in theory it might be expected to reduce the risk of adverse cardiovascular events. If this were to be true then clinically it would be logical to use metformin as a first line agent. The meta-analysis confirms that metformin does significantly reduce fasting insulin and therefore by implication insulin resistance.

Other reported variables of the metabolic syndrome include blood pressure and concentrations of cholesterol and triglycerides. Interpretation of blood pressure is limited by having only 47 participants to analyse, but systolic and diastolic blood pressure were significantly reduced by metformin. Total concentrations of cholesterol, high density lipoprotein cholesterol and triglycerides were all unaffected by metformin, but we found a significant if small reduction in low density lipoprotein cholesterol on the basis of data from 97 participants. Although modest, we believe that

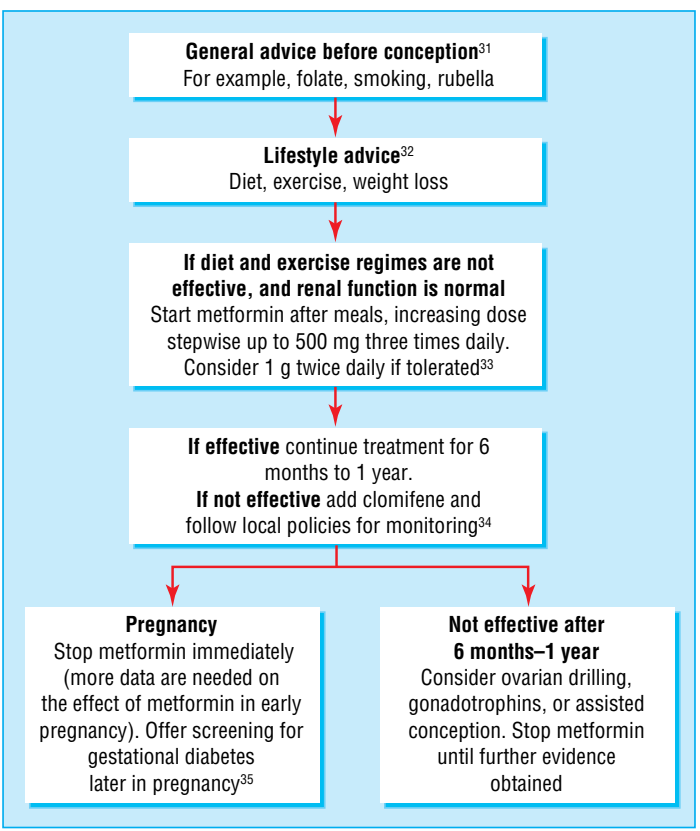

Fig 5 Suggested algorithm for the management of ovulation induction in women with polycystic ovary syndrome

\section{What is already known on this topic}

Polycystic ovary syndrome is characterised by insulin resistance and worsened by obesity

Many trials have reported the use of metformin in polycystic ovary syndrome, but most are observational and involve small numbers of participants

Previous reviews have reached different conclusions about the effectiveness of metformin in treating polycystic ovary syndrome

\section{What this study adds}

This is the first systematic review and meta-analysis of randomised controlled trials in the use of metformin in treating polycystic ovary syndrome

Where metformin is used as a sole agent, ovulation is achieved in $46 \%$ of recipients compared with $24 \%$ in the placebo arm $(\mathrm{NNT}=4.4)$

Where metformin and clomifene are used in combination, $76 \%$ of recipients ovulate compared with $42 \%$ receiving clomifene alone $(\mathrm{NNT}=3.0)$

Metformin has small but beneficial effects on aspects of the metabolic syndrome

There is no evidence that metformin causes weight loss

Equal or better ovulation rates than those achieved by metformin have been described by using lifestyle interventions to achieve weight loss

these benefits in variables known to be associated with adverse cardiovascular risk are further evidence to justify recommending the use of metformin as a first line treatment for anovulation in women with polycystic ovary syndrome.

\section{Contraindications}

Metformin was associated with side effects in the form of nausea, vomiting, and gastrointestinal disturbance. Although no serious adverse events were reported, these side effects limited participation levels in some trials. We found no literature about the safety of long term use of metformin in young women, and no conclusion can be drawn from this review as the longest trial followed up participants for only six months. Metformin is contraindicated in the presence of even mild renal impairment because of a danger of lactic acidosis, and it is associated with decreased absorption of vitamin B12. Experience of metformin in pregnancy has been limited, and, although there is currently no evidence that it is teratogenic, ${ }^{29}$ caution is necessary until its safety in the first trimester has been evaluated more fully.

The overall ovulation rate achieved by metformin or metformin and clomifene was 57\%. Other studies have shown greater ovulation rates with lifestyle improvements that included increased exercise and 
weight loss. ${ }^{30}$ We found no evidence that metformin has an effect on either reducing body mass index or altering the waist:hip ratio. Patients need to be aware that it is not a "weight loss" drug. Metformin should therefore always be used as an adjuvant to general lifestyle improvements and not as a replacement for increased exercise and improved diet. Figure 5 gives suggestions on how to induce ovulation in women with polycystic ovary syndrome. ${ }^{31-35}$

We thank the corresponding authors of trials who took time to respond to our requests for further data, some of whom took the trouble to perform repeat analyses for us. We would also like to thank the Cochrane Menstrual Disorders and Subfertility review group in Auckland, New Zealand, and in particular their co-ordinator Michelle Proctor, for all their help and support. We are also grateful to Andy Vail of the UK Cochrane Centre for statistical advice.

Contributors: JML was responsible for the primary literature search, initial assessment of trials and quality analysis, data collection, analysis, and the initial draft of the full review. He acts as guarantor. IHKF was responsible for developing the protocol, checking the literature search, undertaking secondary assessment of trials and quality analysis (blinded), reviewing data collection and analysis, and revising the first draft of the full review RJN was responsible for developing protocol and was the final arbiter to resolve differences in quality assessment between other reviewers. He contributed to finalising the review and the content and is the Cochrane expert.

Funding: Reproductive Medicine Unit, University of Adelaide. Competing interests: None declared.

1 Hull MGR. Epidemiology of infertility and polycystic ovarian disease: endocrinological and demographic studies. Gyn Endocrinol 1987;1:233end 45 .

2 Polson DW, Adams J, Wadsworth J, Franks S. Polycystic ovaries-a common finding in normal women. Lancet 1988;1: 870-2.

3 Michelmore KF, Balen AH, Dunger DB, Vessey MP. Polycystic ovaries and associated clinical and biochemical features in young women. Clin Endocrinol Oxf 1999;51:779-86.

4 Reaven G. Syndrome X: 10 years after. Drugs 1999;58(suppl 1):S19-82.

5 Legro RS. Diabetes prevalence and risk factors in polycystic ovary syndrome. Obstet Gynecol Clin North Am 2001;28:99-109.

6 Costello MF, Eden JA. A systematic review of the reproductive system effects of metformin in patients with polycystic ovary syndrome. Fertil Steril $2003 ; 79: 1-13$.

7 Harborne L, Fleming R, Lyall H, Norman J, Sattar N. Descriptive review of the evidence for the use of metformin in polycystic ovary syndrome Lancet 2003;361:1894-901.

8 Homburg R. Should patients with polycystic ovarian syndrome be treated with metformin? A note of cautious optimism. Hum Reprod 2002;17:853-6.

9 Nestler JE, Stovall D, Akhter N, Iuorno MJ, Jakubowicz DJ. Strategies for the use of insulin-sensitizing drugs to treat infertility in women with polycystic ovary syndrome. Fertil Steril 2002;77:209-15.

10 Seli E, Duleba AJ. Should patients with polycystic ovarian syndrome be treated with metformin? Hum Reprod 2002;17:2230-6.

11 Stadtmauer LA, Wong BC, Oehninger S. Should patients with polycystic ovary syndrome be treated with metformin?: Benefits of insulin sensitizovary syndrome be treated with metformin?: Benefits of insulin sensitiz-
ing drugs in polycystic ovary syndrome--beyond ovulation induction.

12 Fleming R, Hopkinson ZE, Wallace AM, Greer IA, Sattar N. Ovarian function and metabolic factors in women with oligomenorrhea treated with metformin in a randomized double blind placebo-controlled trial. $J$ Clin Endocrinol Metab 2002;87:569-74.

13 Jakubowicz DJ, Seppala M, Jakubowicz S, Rodriguez-Armas O, Rivas-Santiago A, Koistinen $\mathrm{H}$, et al. Insulin reduction with metformin increases luteal phase serum glycodelin and insulin-like growth factor-binding protein 1 concentrations and enhances uterine vascularity and blood flow in the polycystic ovary syndrome. J Clin Endocrinol Metab 2001;86:1126-39.

14 Kocak M, Caliskan E, Simsir C, Haberal A. Metformin therapy improves ovulatory rates, cervical scores, and pregnancy rates in clomiphene citrate-resistant women with polycystic ovary syndrome. Fertil Steril 2002;77:101-6.

15 Malkawi HY, Qublan HS. The effect of metformin plus clomiphene citrate on ovulation and pregnancy rates in clomiphene-resistant women with polycystic ovary syndrome Saudi Med J 2002;23:663-6.

16 Moghetti P, Castello R, Negri C, Tosi F, Perrone F, Caputo M. et al Metformin effects on clinical features, endocrine and metabolic profiles, and insulin sensitivity in polycystic ovary syndrome: a randomized, double-blind, placebo-controlled 6-month trial, followed by open, long-term clinical evaluation. J Clin Endocrinol Metab 2000;85:139-46.

$17 \mathrm{Ng}$ EHY, Wat NMS, Ho PC. Effects of metformin on ovulation rate, hormonal and metabolic profiles in women with clomiphene-resistant polycystic ovaries: A randomized, double-blinded placebo-controlled trial. Hum Reprod 2001;16:1625-31.

18 Pasquali R, Gambineri A, Biscotti D, Vicennati V, Gagliardi L, Colitta D, et al. Effect of long-term treatment with metformin added to hypocaloric diet on body composition, fat distribution, and androgen and insulin diet on body composition, fat distribution, and androgen and insulin
levels in abdominally obese women with and without the polycystic ovary levels in abdominally obese women with and without
syndrome. J Clin Endocrinol Metab 2000;85:2767-74.

19 Sturrock ND, Lannon B, Fay TN. Metformin does not enhance ovulation induction in clomiphene resistant polycystic ovary syndrome in clinical practice. Br J Clin Pharmacol 2002;53:469-73.

20 Vandermolen DT, Ratts VS, Evans WS, Stovall DW, Kauma SW, Nestler JE. Metformin increases the ovulatory rate and pregnancy rate from clomiphene citrate in patients with polycystic ovary syndrome who are resistant to clomiphene citrate alone. Fertil Steril 2001;75:310-5.

21 Yarali H, Yildiz BO, Demirol A, Zeyneloglu HB, Yigit N, Bukulmez O, et al. Co-administration of metformin during $\mathrm{rFSH}$ treatment in patients with clomiphene citrate-resistant polycystic ovarian syndrome: a prospective randomized trial. Hum Reprod 2002;17:289-94.

22 Nestler JE, Jakubowicz DJ. Decreases in ovarian cytochrome P450c17 alpha activity and serum free testosterone after reduction of insulin secretion in polycystic ovary syndrome. N Engl J Med 1996;335:617-23.

23 Nestler JE, Jakubowicz DJ, Evans WS, Pasquali R. Effects of metformin on spontaneous and clomiphene-induced ovulation in the polycystic ovary syndrome. N Engl J Med 1998;338:1876-80.

24 El-Biely MM, Habba M. The use of metformin to augment the induction of ovulation in obese infertile patients with polycystic ovary syndrome. Middle East Fertil Soc J 2001;6:43-9.

25 Kousta E, White DM, Franks S. Modern use of clomiphene citrate in induction of ovulation. Hum Reprod Update 1997;3:359-65.

26 Messinis IE, Milingos SD. Current and future status of ovulation induction in polycystic ovary syndrome. Hum Reprod Update 1997;3:23553.

27 Levene MI, Wild J, Steer P. Higher multiple births and the modern management of infertility in Britain. Br J Obstet Gynaecol 1992;99:607-13.

28 Reaven GM. Insulin resistance: a chicken that has come to roost. Ann N Y Acad Sci 1999;892:45-57.

29 Hague WM, Davoren PM, Oliver J, Rowan J. Contraindications to use of metformin. Metformin may be useful in gestational diabetes. BMJ 2003:326:762.

30 Clark AM, Thornley B, Tomlinson L, Galletley C, Norman RJ. Weight loss in obese infertile women results in improvement in reproductive outcome for all forms of fertility treatment. Hum Reprod 1998;13:1502-5.

31 Royal College of Obstetrics and Gynaecology. Evidence-based clinical guideline No. 2: the initial investigation and management of the infertile couple. London: RCOG Press, 1998.

32 Norman RJ, Davies MJ, Lord J, Moran LJ. The role of lifestyle modification in polycystic ovary syndrome. Trends Endocrinol Metab 2002;13:251-7.

33 Nestler JE. Metformin and the polycystic ovary syndrome. J Clin Endocrinol Metab 2001;86:1430

34 Royal College of Obstetrics and Gynaecology. Evidence-based clinical guidelines No. 3: the management of infertility in secondary care. London: RCOG Press, 1998

35 Royal College of Obstetrics and Gynaecology. Long-term consequences of polycystic ovary syndrome. London, RCOG, 2003. (Clinical Green Top Guideline No 33.)

(Accepted 7 August 2003) 